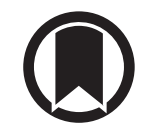

CrossMark

\title{
Genotype alone does not predict the clinical course of SFTPC deficiency in paediatric patients
}

\begin{abstract}
Carolin Kröner ${ }^{1}$, Simone Reu², Veronika Teusch ${ }^{3}$, Andrea Schams ${ }^{1}$, Ann-Christin Grimmelt ${ }^{1}$, Michael Barker ${ }^{4}$, Joerg Brand ${ }^{5}$, Monika Gappa ${ }^{6}$, Richard Kitz ${ }^{7}$, Boris W. Kramer ${ }^{8}$, Lars Lange ${ }^{9}$, Susanne Lau ${ }^{10}$, Claus Pfannenstiel ${ }^{11}$, Marijke Proesmans ${ }^{12}$, Jürgen Seidenberg ${ }^{13}$, Tugba Sismanlar ${ }^{14}$, Ayse Tana Aslan ${ }^{14}$, Claudius Werner ${ }^{15}$, Stefan Zielen ${ }^{5}$, Ralf Zarbock ${ }^{1}$, Frank Brasch ${ }^{16}$, Peter Lohse ${ }^{17}$ and Matthias Griese ${ }^{1}$

Affiliations: ${ }^{1}$ Department of Pediatric Pneumology, Hauner Children's Hospital, Ludwig-Maximilians University, Comprehensive Pneumology Center Munich (CPC-M), German Center for Lung Research (DZL), Munich, Germany. ${ }^{2}$ Department of Pathology, Ludwig-Maximilians University, Munich, Germany. ${ }^{3}$ Department of Pediatric Radiology, Hauner Children's Hospital, Ludwig-Maximilians University, Munich, Germany. ${ }^{4}$ Department of Pediatrics, HELIOS Klinikum Emil von Behring, Berlin, Germany. ${ }^{5}$ Department of Pediatrics, Johann Wolfgang Goethe University, Frankfurt am Main, Germany. ${ }^{6}$ Department of Pediatric Pneumology, Marien-Hospital GmbH, Wesel, Germany. ${ }^{7}$ Department of Pediatric Pneumology, Clementinen Children's Hospital, Frankfurt am Main, Germany. ${ }^{8}$ Department of Pediatrics, Maastricht University Medical Center, Maastricht, Netherlands. ${ }^{9}$ Department of Pediatrics, St. Marien Hospital, Bonn, Germany. ${ }^{10}$ Department of Pediatric Pneumology and Immunology, Charity University, Berlin, Germany. ${ }^{11}$ Pediatric Consultation Center Laurensberg, Aachen, Germany. ${ }^{12}$ Department of Pediatric Pneumology, University Hospital Leuven, Leuven, Belgium. ${ }^{13}$ Department of Pediatric Pneumology, Klinikum Oldenburg gGmbH, Medizinischer Campus Universität Oldenburg, Oldenburg, Germany. ${ }^{14}$ Department of Pediatric Pneumology, Gazi University Hospital, TR-Ankara, Turkey. ${ }^{15}$ Department of Pediatric Pneumology, University Hospital Münster, Münster, Germany. ${ }^{16}$ Department of Pathology, Academic Teaching Hospital Bielefeld, Bielefeld, Germany. ${ }^{17}$ Institute of Laboratory Medicine and Human Genetics, Singen, Germany.
\end{abstract}

Correspondence: M. Griese, Hauner Children's Hospital, Ludwig-Maximilians-University Munich Lindwurmstraße 4, D-80337 Munich, Germany. E-mail: matthias.grieselamed.uni-muenchen.de

ABSTRACT Patients with interstitial lung disease due to surfactant protein C (SFTPC) mutations are rare and not well characterised.

We report on all subjects collected over a 15 -year period in the kids-lung register with interstitial lung disease and a proven SFTPC mutation. We analysed clinical courses, interventions and outcomes, as well as histopathological and radiological interrelations.

17 patients (seven male) were followed over a median of 3 years (range 0.3-19). All patients were heterozygous carriers of autosomal dominant SFTPC mutations. Three mutations (p.L101P, p.E191 K and p.E191*) have not been described before in the context of surfactant protein C deficiency. Patients with alterations in the BRICHOS domain of the protein (amino acids 94-197) presented earlier. At follow-up, one patient was healthy (2 years), six patients were "sick-better" (2.8 years, range 0.8-19), seven patients were "sick-same" (6.5 years, 1.3-15.8) and three patients were "sick-worse" (0.3 years, 0.3-16.9). Radiological findings changed from ground-glass to increasing signs of fibrosis and cyst formation with increasing age. Empiric treatments had variable effects, also in patients with the same genotype.

Prospective studies with randomised interventions are urgently needed and can best be performed in the framework of international registers.

@ERSpublications

Genotype alone does not predict the clinical course of surfactant protein $\mathrm{C}$ deficiency in children and young adults http://ow.ly/GRhCc

This article has supplementary material available from erj.ersjournals.com

Received: July 162014 | Accepted after revision: Dec 052014 | First published online: Feb 052015

Conflict of interest: None declared.

Copyright OERS 2015 


\section{Introduction}

Interstitial lung diseases (ILD) in children represent a broad array of clinical entities. Only for some distinct groups is the cause known [1]. The surfactant dysfunction disorders are the group best defined molecularly, since the discovery of mutations in genes involving surfactant proteins with important functions in the lungs. Among these proteins is surfactant protein (SP) C, a hydrophobic protein critical for surfactant homeostasis, encoded by the surfactant protein C gene (SFTPC) on chromosome 8p21.3 and expressed as a pro-protein in type II pneumocytes. After extensive post-translational processing, mature SP-C is secreted into the alveolar space [2]. Since the first description of ILD being associated with an alteration of the SFTPC gene in 2001 [3], about 50 different mutations have been reported [4], mainly as case reports and small series.

The most common mutation is p.I73T (c.218T >C), which hampers the secretion of SP-C through aberrant protein folding and intracellular processing [2]. Mutations are also located in the so called BRICHOS domain, which is a highly conserved region at the C-terminal end (p.F94-p.I197) of the SP-C pro-protein [4]. This domain normally prevents the protein from forming amyloid-like fibrils [5], which deposit in patients with SP-C-related ILDs as insoluble, fibrillar $\beta$-sheet polymers [6]. Lung disease caused by different SFTPC mutations covers a broad range of phenotypes [7-10]. Whether mutation-specific pathophysiological mechanisms are associated with distinct clinical phenotypes remains elusive. The total number of reported cases per mutation is still very low, and the phenotypic description of these cases is frequently not complete. We intended to widen the spectrum of genetically defined patients and to provide details on the individual disease courses as well as the histopathological and radiological findings in order to allow more precise estimates of outcomes and effects of therapeutic interventions.

\section{Methods}

Patients

All children identified in the programme for rare lung diseases of the Kids-Lung Register (Hauner Children's Hospital, Munich, Germany) between 1998 and 2013 with a heterozygous dominant mutation in the SFTPC gene were included in this study. 17 patients were identified, including three monozygous triplets. Three patients $(5,12$ and 15) have been reported previously [11-13], but were included into this cohort because of additional information. Retrospective and prospective clinical data were collected since the start of the study. In addition, bronchoalveolar lavage (BAL) levels of SP-C and SP-B were determined, and lung biopsy specimens as well as radiological studies were evaluated. The study was approved by the Ethics committee of the University of Munich (Munich, Germany) (Protocol 257-10). All parents or the guardians of the children gave their informed consent, and an older youth assented.

\section{Clinical follow-up}

The following definitions were used to group patients into follow-up groups. The status was compared with the beginning of the individual observation periods: "sick-worse" was used for patients with a worse clinical status (more severe symptoms), "sick-same" for patients with the same clinical status (same degree of severity of symptoms), "sick-better" was defined as an improvement of clinical status (less therapy, less symptoms) and "healthy" was defined as having had no clinical symptoms and no therapy for at least 12 months.

\section{Genetic analysis of the SFTPC gene}

The five protein-coding exons of the SFTPC gene were amplified via PCR and sequenced by standard methods.

\section{Structure-function analysis of novel SFTPC mutations}

In silico prediction of the effect of SFTPC mutations on protein function was performed with the computer programmes PROVEAN [14], SIFT [15] and PolyPhen2 [16]. Conservation of amino acids across species was determined by comparison of the SP-C sequences of Homo sapiens, Mus musculus, Bos taurus, Rattus norvegicus, Sus scrofa, Pan troglodytes, Felis catus, Columba livia and Xenopus tropicalis.

\section{Analysis of total protein and of SP-B and SP-C concentration in BAL}

Total protein was measured using the Bradford method as described previously [16]. SP-B and SP-C were determined as described $[17,18]$ : proteins were separated on NuPage $10 \%$; Bis-Tris gels (Novex X-cell Ii Mini Cell System; Novex, San Diego, CA, USA), transferred onto nitrocellulose membranes by Western

Support statement: Funding for this study was provided by Bundesministerium für Bildung und Forschung (Goldnet), Deutsche Forschungsgemeinschaft (970/8-1), European Union (Child-EU; FP7, No. 305653), and Else KrönerFresenius-Stiftung (A72/2013). Funding information for this article has been deposited with FundRef. 
blot in Nupage Blot modules (Novex) and incubated with antibodies as described [17]. For quantification, two standards were run on each gel; SP-B at 10 and $20 \mathrm{ng}$ and SP-C at 10 and $25 \mathrm{ng}$. The assay for SP-B was linear between 1 and $40 \mathrm{ng}$, the one for SP-C between 3 and $80 \mathrm{ng}$. The inter-assay coefficient of variation was $10 \%$ for SP-B and $19 \%$ for SP- C. The membranes were activated with an enhanced chemiluminescence assay and exposed to X-ray films (Hyperfilm ECL; Amersham Biosciences, Amersham, UK). After development of the films, bands were quantified using the Diana III chemiluminescence detection system and Advanced Image Data Analyzer software, Version 4.04.032 (Raytest, Straubenhardt, Germany).

\section{Lung biopsy and histopathology}

All available lung biopsies were collected as paraffin blocks or as histopathological slides. The slides were examined by a pathologist (F. Brasch) experienced in the field of paediatric ILD. They were then independently scored by a second pathologist (S. Reu) specialising in pulmonary diseases.

\section{Radiological studies}

All available radiological studies were reviewed and scored by a paediatric radiologist according to the criteria of the Fleischner Society [19]. Computed tomography (CT) scans were rated in six areas. Each lung was divided into three sections: apex to carina; carina to lower pulmonary vein; and lower pulmonary vein to diaphragm. The incidence of hilar lymph nodes, ground glass opacities, cysts, peribronchial thickening, bronchiectasis, honeycombing, interlobular septal thickening, intralobular septal thickening, crazy paving, paraseptal emphysema/hyperinflation, nodular opacities, lobe retraction and consolidations was evaluated for each lung section. The findings were graded into four levels according to the severity (none, mild, moderate and extensive).

\section{Statistical analysis}

Fisher's exact test and the Mann-Whitney test (GraphPad Prism, version 4.00; GraphPad Software, San Diego, CA, USA) were used to compare frequencies between patient groups. Fisher's exact test was used to analyse contingency tables. The unpaired t-test (GraphPad Prism) was used to compare the means of CT scan rating between different groups. A p-value $\leq 0.05$ was considered significant.

\section{Results \\ Clinical presentation}

About half of the 17 patients presented with neonatal respiratory symptoms. The others had respiratory symptoms during infancy or later (table 1 , and table s1 and fig. s1 in the online supplementary material). Failure to thrive was the most important extra-pulmonary manifestation (15 out of 17 patients) and treated in subjects by percutaneous endoscopic gastrostomy tube in 10 subjects.

\section{Genetic results}

All 17 patients were of Caucasian descent; eight patients carried the hot spot mutation p.I73T (table 2, and table s1 and fig. s2 in the online supplementary material). Eight patients had sequence alterations, likely to be damaging enough to explain the phenotype, except in patient 17 (table 2, and table s2 in the online supplementary material). In this patient (compound heterozygous p.L101P; p.E191K), genetic analysis of relatives revealed that the grandfather carried p.L101P and suffered from usual interstitial pneumonia (UIP), while the patient's mother (also carrying p.L101P) was reported to be healthy. The patient's father, in contrast, was heterozygous for p.E191K and healthy. This amino acid is conserved among mammals and its exchange is predicted to be possibly damaging. In total, 10 patients had de novo and three familial mutations, while four parents refrained from genetic testing (table 2).

\section{Follow-up}

Median (range) follow-up was 3 years (0.3-19) (table 3). Empiric therapy included neonatal surfactant, corticosteroids (continuous and pulse therapy), colchicine, hydroxychloroquine, antibiotic therapy including azithromycin and whole lung lavage for initial alveolar proteinosis presentation. One patient received a left lung volume reduction due to the development of bullous emphysema. The effect of therapy was judged retrospectively based on patient reports. Therapy with hydroxychloroquine moderately improved the clinical course in six patients and had a good effect in another six individuals, shortly after initiation of therapy (table 4, and table s3 in the online supplementary material). Only two patients developed significant side effects: one patient (12) developed an erythema exsudativum multiforme after the start of hydroxychloroquine and one patient (17) developed Cushing's syndrome under steroid therapy.

Overall, the patients' outcomes were classified as healthy in one (patient 4, p.I73T, after 2 years), sick-same in seven patients (median 6.5 years, range 1.3-15.8), sick-better in six patients (median 2.8 years, range 
TABLE 1 Clinical presentation of 17 patients with SFTPC mutations

\begin{tabular}{|c|c|c|c|c|c|c|c|c|}
\hline n & $\begin{array}{l}\text { Female/ } \\
\text { male } \mathrm{n}\end{array}$ & $\begin{array}{l}\text { Gestational } \\
\text { age }\end{array}$ & Age at onset & $\begin{array}{l}\text { Neonatal } \\
\text { symptoms } n\end{array}$ & Post neonatal symptoms $\mathrm{n}$ & $\begin{array}{l}\text { Mechanical } \\
\text { ventilation } \mathrm{n} \text { (age) }\end{array}$ & Failure to thrive $\mathrm{n}$ & $\begin{array}{l}\text { Other } \\
\text { diagnosis } \mathrm{n}\end{array}$ \\
\hline \multicolumn{9}{|c|}{ All patients } \\
\hline 17 & $10 / 7$ & $\begin{array}{l}39 \text { (36-43) } \\
\text { weeks }\end{array}$ & $\begin{array}{l}2 \text { (0-132) } \\
\text { months }\end{array}$ & $\begin{array}{l}9 \text { yes, of whom: } 3 \\
\text { RDS; } 4 \text { tachy/ } \\
\text { dyspnoea; } 1 \\
\text { cyanosis; } 1 \\
\text { staphylodermia }\end{array}$ & $\begin{array}{l}17 \text { yes, of whom: } 17 \text { tachypnoea, } \\
\text { oxygen demand; } 3 \text { spontaneous } \\
\text { pneumothorax; } 2 \text { persistent } \\
\text { pulmonary hypertension; } 2 \\
\text { cyanosis; } 5 \text { abnormal skeletal } \\
\text { thorax; } 17 \text { recurrent infections of } \\
\text { which: } 5 \text { RSV pneumonia; } 2 \\
\text { Chlamydophilia pneumoniae } \\
\text { pneumonia; } 3 \text { Pseudomonas } \\
\text { aeruginosa pneumonia; } 1 \\
\text { influenza pneumonia; } 1 \text { chronic } \\
\text { disseminated cytomegalovirus } \\
\text { infection; } 1 \text { methicillin-resistant } \\
\text { Staphylococcus aureus pneumonia }\end{array}$ & 11 (1 (0-24) month) & $\begin{array}{l}15 \text { yes, of whom: } 9 \\
\text { percutaneous endoscopic } \\
\text { gastrostomy; } 4 \\
\text { gastro-oesophageal reflux } \\
\text { disease; } 1 \text { cow milk } \\
\text { allergy }\end{array}$ & $\begin{array}{l}10 \text { yes, of } \\
\text { whom: } \\
5 \text { cardiac } \\
\text { anomalies; } \\
2 \text { mental } \\
\text { retardation; } \\
8 \text { other } \\
\text { diagnosis } \#\end{array}$ \\
\hline \multicolumn{9}{|c|}{$\begin{array}{l}\text { Non-BRICHOS } \\
\text { domain } \\
\text { mutations }\end{array}$} \\
\hline 10 & $6 / 4$ & $\begin{array}{l}39(36-40) \\
\text { weeks }\end{array}$ & $\begin{array}{l}0.3(0-11) \\
\text { years }\end{array}$ & 3 yes, 1 unknown & 10 yes & $\begin{array}{l}7 \text { yes ( } 4.8 \\
(0-24) \text { months) }\end{array}$ & 9 yes & $\begin{array}{l}4 \text { yes, } 1 \\
\text { unknown }\end{array}$ \\
\hline \multicolumn{9}{|l|}{$\begin{array}{l}\text { BRICHOS } \\
\text { domain } \\
\text { mutations }\end{array}$} \\
\hline 7 & $4 / 3$ & $\begin{array}{l}39(36-43) \\
\text { weeks }\end{array}$ & $\begin{array}{l}0 \text { (0-3) } \\
\text { months }\end{array}$ & 6 yes & 7 yes & $\begin{array}{l}4 \text { yes }(0 \\
(0-19) \text { months })\end{array}$ & 5 yes & 5 yes \\
\hline p-value & & & & 0.06 & NS & NS & NS & NS \\
\hline
\end{tabular}

Data are presented as median (range), unless otherwise stated. RDS: respiratory distress syndrome; RSV: respiratory syncytial virus; PEG: percutaneous endoscopic gastrostomy; Ns: not significant. \# : see table s1 in the online supplementary material " : Fisher's exact test comparing frequencies between BRICHOS/non-BRICHOS mutations. 
TABLE 2 Genetic information and family history of 17 patients with SFTPC mutations

\begin{tabular}{|c|c|c|c|c|}
\hline Patient & Mutation & $\begin{array}{c}\text { De novo or inherited } \\
\text { mutation }\end{array}$ & Consanguinity & Family history \\
\hline $1^{\#}$ & p.I73T & De novo & No & $\begin{array}{l}\text { Father and grandfather: } \\
\text { Barrett's oesophagus }\end{array}$ \\
\hline $2^{\#}$ & p.I73T & De novo & No & $\begin{array}{l}\text { Father and grandfather: } \\
\text { Barrett's oesophagus }\end{array}$ \\
\hline $3^{\#}$ & p.I73T & De novo & No & $\begin{array}{l}\text { Father and grandfather: } \\
\text { Barrett's oesophagus }\end{array}$ \\
\hline 4 & p.I73T & De novo & No & No \\
\hline 5 & p.I73T & De novo & No & No \\
\hline 6 & p.I73T & Unknown & No & 2 abortions, 1 postnatal death \\
\hline 7 & p.I73T & De novo & Yes & No \\
\hline 8 & p.I73T & Unknown & Unknown & $\begin{array}{l}\text { Mother: thalassaemia minor, G5P2 } \\
\text { (five pregnancies, two live births), } \\
\text { hyperprolactinaemia, intrauterine fetal } \\
\text { death; father: haemoglobin E } \\
\text { haemoglobinopathy; parents: } \\
\text { cow milk's protein intolerance }\end{array}$ \\
\hline 9 & p.H59R & $\begin{array}{l}\text { Father H59R, mother } \\
\text { negative, brother } \\
\text { negative }\end{array}$ & Yes & $\begin{array}{c}\text { Father healthy, brother: spontaneous } \\
\text { pneumothorax at age } 19 \text { years, bullous } \\
\text { paraseptal emphysema }\end{array}$ \\
\hline 10 & p.E191*ף & De novo & No & No \\
\hline 11 & p.G74V & De novo & Yes & No \\
\hline 12 & p.C121F & De novo & No & No \\
\hline 13 & p.A112T & Unknown & Unknown & No \\
\hline 14 & p.C121F & Unknown & No & No \\
\hline 15 & p.C121G & De novo & No & No \\
\hline 16 & $\begin{array}{l}\text { p.A53T and } \\
\text { p.L181V }\end{array}$ & $\begin{array}{l}\text { Father p.A53T and } \\
\text { p.L181 V, sister } \\
\text { unknown }\end{array}$ & No & $\begin{array}{l}\text { Mother: asthma, atopic dermatitis, } \\
\text { neurinoma, gestational diabetes, one } \\
\text { abortion; father: atopic dermatitis, } \\
\text { recurrent otitis, sister: recurrent otitis }\end{array}$ \\
\hline 17 & $\begin{array}{l}\text { p.L101P } \\
\text { and } \\
\text { p.E191K }\end{array}$ & $\begin{array}{l}\text { Mother, grandfather } \\
\text { p.L101P, father } \\
\text { p.E191 K }\end{array}$ & No & Grandfather: usual interstitial pneumonia \\
\hline
\end{tabular}

\#: monozygous triplets; " : novel mutations.

\section{TABLE 3 Follow-up of 17 patients with SFTPC mutations}

Age at last observation

$3(0.3-19)$ years

\section{Symptoms at last observation lage)}

2 global respiratory insufficiency, mechanical ventilation ( 0.3 and 0.8 years) 1 fibrosis, listed for lung transplantation (16.9 years)

1 home ventilation, mainly at night (1.3 years)

4 hypoxia (6.5 (6.5-13) years)

3 mild tachypnoea $(0.8,1.6$ and 2.6 years $)$

1 hypoxaemia with exercise (15.8 years)

1 severe pneumonia in past years (19 years)

2 mild upper airway infections ( 3 and 6.7 years)

1 oxygen demand during infection (2.5 years)

1 healthy (2 years)

Data are presented as median (range).

0.8-19) and sick-worse in three patients (at $0.3,0.8$ and 16.9 years) (table 3, and table s3 in the online supplementary material). All patients survived. The localisation of the mutations inside or outside the BRICHOS domain did not affect the outcome. 
TABLE 4 Therapy and response of 17 patients with SFTPC mutations

\begin{tabular}{lcc} 
Treatment & Patients $\mathbf{n}$ & BRICHOS/non-BRICHOS mutation $\mathbf{n}$ \\
\hline Surfactant treatment & 10 & $4 / 6$ \\
Not done & 5 & $4 / 1$ \\
No improvement & 1 & $0 / 1$ \\
Moderate improvement & 1 & $0 / 1$ \\
Good response & & \\
Systemic steroids & 2 & $2 / 0$ \\
Not done & 1 & $1 / 0$ \\
No improvement & 13 & $5 / 8$ \\
Moderate improvement & 1 & $0 / 1$ \\
Good response & 14 & $11 / 3$ \\
Colchicin & 3 & $0 / 3$ \\
Not done & 0 & 0 \\
No improvement & 0 & 0 \\
Moderate improvement & & $1 / 2$ \\
Good response & 3 & $1 / 1$ \\
Hydroxychloroquine & 2 & $2 / 4$ \\
Not done & 6 & $4 / 2$ \\
No improvement & 6 & $7 / 10$ \\
Moderate improvement & & $2 / 6$ \\
Good response & 17 & $1 / 4$ \\
Other treatments & 8 & $0 / 1$ \\
Antibiotic therapy & 5 & $2 / 5$ \\
Azithromycin & 1 & $5 / 2$ \\
Whole lung lavage & 3 & \\
Left lung volume reduction & & \\
General response to all treatments at end & & \\
of observation & & \\
No long-term treatment & & \\
Moderate improvement & & \\
Good improvement & & \\
& &
\end{tabular}

TABLE 5 Analysis of surfactant proteins B (SP-B) and C (SP-C) from bronchoalveolar lavage fluid

\begin{tabular}{|c|c|c|c|c|c|c|}
\hline \multirow[t]{2}{*}{ Patient } & \multirow{2}{*}{$\begin{array}{c}\text { Age at BAL } \\
\text { years }\end{array}$} & \multicolumn{2}{|c|}{ SP-C ng mL $\mathrm{mL}^{-1}$} & \multicolumn{3}{|c|}{ SP-B ng mL $\mathrm{mL}^{-1}$} \\
\hline & & $4 \mathrm{kDa}$ & 8 kDa & 8 kDa & 16 kDa & $24 \mathrm{kDa}$ \\
\hline 1 & 1 & 16 & 16 & 400 & 533 & yes \\
\hline 5 & 1.9 & 58 & 223 & & 2316 & 421 \\
\hline 5 & 4.1 & 0 & 0 & & 723 & 275 \\
\hline 8 & 0.5 & 120 & 56 & 0 & 1697 & 494 \\
\hline 10 & 0.1 & 0 & 0 & & 370 & 673 \\
\hline 10 & 0.4 & 0 & 0 & 536 & 506 & 413 \\
\hline 11 & 19.2 & 14 & 0 & & 229 & 216 \\
\hline 12 & 1.3 & 0 & 0 & & 1941 & Yes \\
\hline 14 & 0.5 & 0 & 0 & & 26 & Yes \\
\hline 17 & 0.1 & 0 & 0 & 0 & 1326 & 1350 \\
\hline Mean士sE & $2.9 \pm 1.8$ & $20.8 \pm 12.4$ & $29.5 \pm 22.2$ & $234 \pm 138$ & $967 \pm 251$ & $549 \pm 145$ \\
\hline $\begin{array}{l}\text { Reference values in } \\
\text { healthy children } \\
\text { mean士sE; } n\end{array}$ & & $\begin{array}{c}116 \pm 14 \\
61\end{array}$ & $\begin{array}{c}140 \pm 81 \\
26\end{array}$ & $\begin{array}{c}68 \pm 22 \\
13\end{array}$ & $\begin{array}{c}580 \pm 53 \\
\quad 67\end{array}$ & $\begin{array}{c}288 \pm 89 \\
18\end{array}$ \\
\hline
\end{tabular}

BAL: Bronchoalveolar lavage

Surfactant proteins in BAL fluid

BAL data were available for eight patients. Mature SP-C $(4 \mathrm{kDa})$ was lacking in all six patients with BRICHOS domain mutations and available BAL. In patients with p.I73T, SP-C was present at young age, in particular when alveolar proteinosis was demonstrated histologically, but not later. SP-B was present in 


\begin{tabular}{|c|c|c|c|c|}
\hline & At diagnosis & Early follow up & Late follow up & p-value ${ }^{\pi}$ \\
\hline Available studies & 6 & 6 & 4 & \\
\hline Mean (range) age at investigation years & $0.4(0.1-0.7)$ & $1.4(0.9-2.0)$ & $14.2(8.3-19.2)$ & \\
\hline Hilar lymphnodes (present/all invest) & $1 / 6$ & $2 / 6$ & $2 / 4$ & NS \\
\hline Ground glass opacities" & 1.9 & 1.8 & 0.2 & 0.011 \\
\hline Cysts" $\#$ & 0.2 & 0.5 & 2.6 & $<0.001$ \\
\hline Peribronchial thickening & 0.1 & 0.5 & 0.2 & 0.006 \\
\hline Bronchiectasis & 0.8 & 1 & 0.4 & NS \\
\hline Honeycombing & 0 & 0.3 & 1.5 & NS \\
\hline Interlobular septal thickening & 0 & 0.1 & 0 & NS \\
\hline Intralobular septal thickening & 1.5 & 1.2 & 1.5 & NS \\
\hline Crazy paving & 0.7 & 0.3 & 0 & NS \\
\hline Paraseptal emphysema/hyperinflation & 0 & 0 & 0.8 & NS \\
\hline Nodular opacities & 0.1 & 0 & 0 & NS \\
\hline Lobe retraction & 0 & 0 & 0 & NS \\
\hline Attenuations & 0 & 0.1 & 0.1 & NS \\
\hline
\end{tabular}

\#: Scans were rated in six areas lapex to carina, carina to lower pulmonary vein, below pulmonary vein on left and right side) for the indicated findings as none $=0$, mild $=1$, moderate $=2$ and severe $=3$; the results were averaged per CT scan in an individual subject and the mean values were calculated for the number of subjects indicated. ": Explorative comparison between "at diagnosis" and "late follow up" by unpaired t-test. NS: not significant ( $p>0.05)$.

all patients as a physiological dimer $(16 \mathrm{kDa})$. Its concentration was relatively low in three patients and elevated in two (table 5 , and table s4 in the online supplementary material).

\section{Radiology}

Six early CT scans were available, six at early follow-up and four at late follow-up (table 6). During the first 9 months ground glass pattern was present in all investigated patients in addition to intralobular septal thickening and a mild degree of cysts and bronchiectasis. At follow up, ground glass pattern was less prominent, giving way to increased signs of fibrosis, including bronchial wall thickening and more severe development of cysts (table 6 and fig. 1, and fig. $s 3$ in the online supplementary material). Differentiation between BRICHOS and non-BRICHOS domain mutations was not possible due to the limited number of available studies. Two patients (patients 9 and 13) showed the typical features of a combined pulmonary fibrosis and emphysema syndrome (CPFE), an entity which has recently been recognised [20]. Both patients had pronounced upper lobe emphysema at ages 13.6 and 19.2 years and signs of fibrosis, including intralobular septal thickening, diffuse honeycombing, and cyst formation.

FIGURE 1 Exemplary radioimaging of two patients with surfactant protein C mutations. a, b) chest radiograph and computed tomography scan of patient 1 at 18 months showing diffuse ground glass pattern and interstitial thickening. c, d) chest radiograph and computed tomography scan of patient 9 at 13.6 years showing emphysema, cysts, bullae and left-sided pneumothorax.
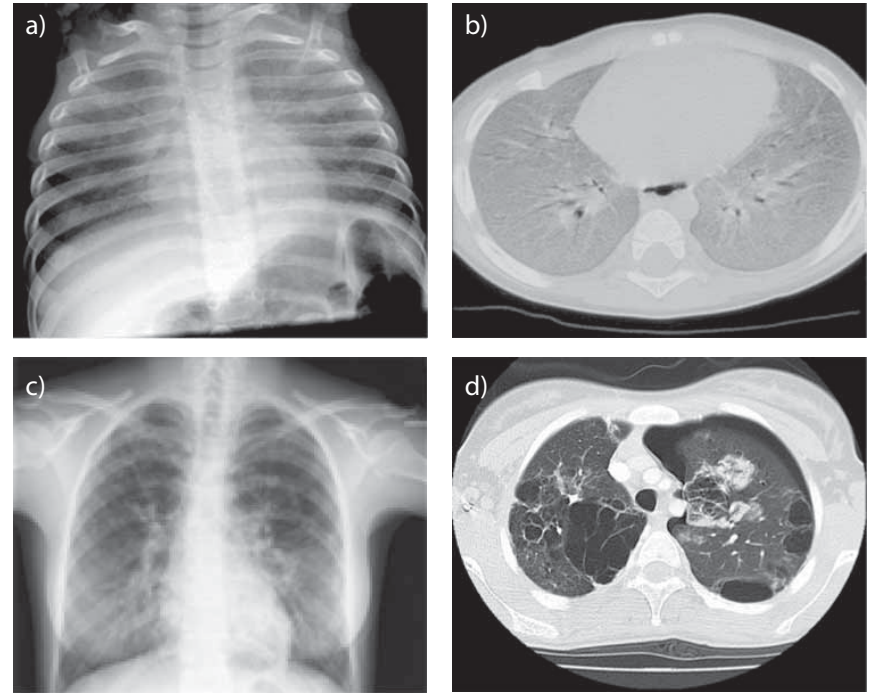
TABLE 7 Histological classification, mutation and age at biopsy of patients with SFTPC mutations and lung biopsy

\begin{tabular}{|c|c|c|c|}
\hline Histological picture & Patient & Mutation & Age at biopsy years \\
\hline \multirow[t]{3}{*}{ PAP } & 5 & p. $173 T^{\#}$ & 1.2 \\
\hline & $11^{\pi}$ & p.G74V\# & 0.3 \\
\hline & $13^{\pi}$ & p.A112T & 0.3 \\
\hline \multirow[t]{5}{*}{ NSIP } & 2 & p.173T" & 0.5 \\
\hline & $7^{\text {ๆ }}$ & p. $173 T^{\#}$ & 2.2 \\
\hline & 9 & p.H59R $\#$ & 13.7 \\
\hline & $14^{\text {? }}$ & p.C121F & 0.3 \\
\hline & 17 & p.L101P $\mathrm{P}^{+}$and p.E191K $\mathrm{K}^{+}$ & 0.1 \\
\hline \multirow[t]{2}{*}{ Combined NSIP, PAP, DIP } & $8^{\S}$ & p. $173 \mathrm{~T}^{\#}$ & 0.5 \\
\hline & 10 & p.E191*+ & 0.8 \\
\hline
\end{tabular}

PAP: pulmonary alveolar proteinosis; NSIP: non-specific interstitial pneumonia; DIP: desquamative interstitial pneumonia. " : BRICHOS mutations; ๆ: only report available; ${ }^{+}$: novel mutations; ${ }^{\S}$ : reviewer scored NSIP only.

\section{Histopathology}

Lung biopsies were done in 10 subjects (table 7, and table s5 in the online supplementary material), available for review in six patients; in four patients only written results of the lung biopsies were available. Most patients had a combined picture of interstitial fibrosis and interstitial chronic inflammation, type II pneumocyte hyperplasia, alveolar septal thickening, inflammation, enlargement as well as alveolar macrophage and material accumulation, and the accumulation of mesenchymal cells in the alveolar interstitium. Histological pattern identified were pulmonary alveolar proteinosis (PAP) (three patients) and non-specific interstitial pneumonia (NSIP) (five patients) and combined NSIP, PAP and desquamative interstitial pneumonia (DIP) (two patients). In four patients (2, 5, 8 and 17) both, report and biopsy material were available. Histological pattern recognized by two pathologists were identical in patients 2,5 and 17, for patient 8 one pathologist classified as NSIP, one pathologist as a combined picture of NSIP, DIP and PAP (table 7).

\section{Discussion}

The goal of this study was to increase the number of genetically defined patients with SP-C deficiency, to provide detailed patient information, and to identify recognisable patterns which may be helpful for the physician to identify such rare individuals in clinical practice. The diagnosis of ILD as a consequence of SFTPC mutations is not easy due to the variable clinical presentation; however, indispensable knowledge of the phenotypes and a sufficient index of suspicion can serve to initiate specific genetic testing in order to rule out or confirm the suspected diagnosis. From our cohort, together with the experiences reported by others, we can differentiate three periods with different but typical characteristics depending on the age of the subject.

The first type of presentation is neonatal respiratory distress syndrome, mostly in the mature neonate. In our series patients with a mutation in the BRICHOS domain present more frequently in the first week of life, confirming the results of one other study [8]. These patients also require early mechanical ventilation. Family history may reveal lung disease, previous abortions or postnatal death in about one-third of cases.

A second type of presentation is the infant with tachydyspnoea (seven out of 17 of our patients) and failure to thrive (eight out of 17). The start of symptoms was often insidious (seven out of 17 of our patients) and possibly triggered by a viral infection (six out of 17). On chest CT imaging, ground-glass pattern is the predominant finding in patients during the first 6-9 months of age. If histology was done, a pattern of PAP, NSIP and DIP was observed, alone and in combination. This is consistent with other studies [8].

The third, late-onset type of presentation from later childhood to adolescence or even adulthood is characterised by tachydyspnoea, hypoxia and possibly repeated infections. This agrees with case reports describing manifestation of SFTPC mutations in adults with interstitial lung disease [10, 21, 22]. However, it may well be that several of these patients are not diagnosed earlier due to reduced perception of signs or are lost during follow-up.

Clinical outcome at follow-up varied from healthy (age 2 years) to persistent severe respiratory insufficiency (age 0.3 and 16.9 years) and was not associated with the type of mutation, the location in the 
BRICHOS domain, or the age at presentation. SFTPC mutations have been described before with severity varying from neonatal respiratory insufficiency [9] to children and adults with mild-to-severe ILD [3, 23-25]. In an elegant study, follow-up of five patients with SFTPC mutations was reported after three decades, as previously published cases can be genetically analysed later [10]. Three subjects (p.I38T, p.I73T and p.V39L) had no pulmonary symptoms at age 29, 32, and 37 years, respectively, and two (p.I73T) suffered from stable interstitial lung disease at age 28 and 32 years.

It is obvious that the phenotype of SP-C deficiency is not predicted by the SFTPC mutation alone. It is likely that other genes and also environmental factors, including viral infections, may strongly influence the disease course. Therefore, it is difficult in single cases to judge on the significance of some sequence variations. In the present study, we had two complex genotypes: in patient 17, the two p.L101P and p.E191K mutations were located in trans, as demonstrated by investigations of the parents and were predicted to be at least possibly damaging. In patient 16, carrying p.A53T and p.L181V was likely disease-causing, as the leucine is highly conserved across species and the variation is predicted to be protein damaging or probably damaging by SIFT and PolyPhen-2. Additionally, p.L181V has been reported in one adult with idiopathic pulmonary fibrosis (IPF) [26] and in one child with ILD [27]. In an epidemiological study, p.A53T in contrast was associated with a two-fold increased risk of asthma [28], but not ILD or chronic obstructive pulmonary disease.

Imaging over time by CT scan revealed significant changes from initial homogeneous ground glass attenuation to increasing signs of fibrosis with honeycombing, peribronchial, interlobular, and intralobular septal thickening as well as cyst formation. Qualitatively similar observations have been made in other cohorts $[7,8]$. Interestingly, patients 9 and 13 exhibited typical features of a CPFE, an entity which was only recently recognised [20]. CPFE is reported to be associated especially with smoking, male sex, IPF, hypersensitivity pneumonitis, asbestosis and connective tissue disorders [20]. One recent case report described CPFE in a 32-year-old woman with a familial I73T mutation [22]. Here, we add two more patients with SFTPC mutations (p.H59R and p.A112T) and typical radiological features of combined upper lobe emphysema and fibrosis. Patient 9 required a left lung volume reduction due to the emphysema.

Biochemical analysis of BALF for SP-C yielded low or absent levels and as such directs the suspicion towards surfactant dysfunction disorders. However, although indicative of a SFTPC mutation, this finding is not specific, as reduced values have also been described in SP-B [29] and ABCA3 (ATP-binding cassette, sub-family A (ABC1), member 3) deficiency [30].

Empirical treatment with various drugs is frequently done and the results reported here may suggest some efficacy for hydroxychloroquine. Thus, in a first step, a randomised controlled trial is needed to investigate an overall effect, followed by a mutation and a stage-specific evaluation. Such studies are currently in preparation (www.childeu.net).

\section{Acknowledgements}

We thank Traudl Wesselak (Department of Pediatric Pneumology, Hauner Children's Hospital, Ludwig-Maximilians University, Munich, Germany) who helped in assembling the patient data. The work of Matthias Griese was supported by DFG-970/8-1, BMBF-Goldnet, chILD-EU (FP7, No. 305653) and the "Else Kröner-Fresenius-Stiftung".

C. Kröner, A-C. Grimmelt, R. Zarbock and M. Griese conceived and designed the study and collected and analysed the data. S. Reu and F. Brasch diagnosed, analysed and scored the histological material. V. Teusch diagnosed, analysed and scored the radiological imaging. A. Schams, M. Griese and R. Zarbock performed the biochemical analysis. P. Lohse performed the sequencing of the SFTPC gene. C. Kröner, A-C. Grimmelt, M. Griese, M. Barker, J. Brand, M. Gappa, R. Kitz, BW. Kramer, L. Lange, S. Lau, C. Pfannenstiel, M. Proesmans, J. Seidenberg, T. Sismanlar, C. Werner and S. Zielen provided patient information and material. C. Kröner and M. Griese drafted the manuscript and all authors critically revised, read and approved the final manuscript. M. Griese is responsible for the study concept and validity of the data.

\section{References}

1 Deutsch GH, Young LR, Deterding RR, et al. Diffuse lung disease in young children: application of a novel classification scheme. Am J Respir Crit Care Med 2007; 176: 1120-1128.

2 Devine MS, Garcia CK. Genetic interstitial lung disease. Clin Chest Med 2012; 33: 95-110.

3 Nogee LM, Dunbar AEIII, Wert SE, et al. A mutation in the surfactant protein C gene associated with familial interstitial lung disease. N Engl J Med 2001; 344: 573-579.

4 Willander H, Askarieh G, Landreh M, et al. High-resolution structure of a BRICHOS domain and its implications for anti-amyloid chaperone activity on lung surfactant protein C. Proc Natl Acad Sci USA 2012; 109: 2325-2329.

5 Knight SD, Presto J, Linse S, et al. The BRICHOS domain, amyloid fibril formation, and their relationship. Biochemistry 2013; 52: 7523-7531.

6 Willander H, Presto J, Askarieh G, et al. BRICHOS domains efficiently delay fibrillation of amyloid beta-peptide. J Biol Chem 2012; 287: 31608-31617.

7 Mechri M, Epaud R, Emond S, et al. Surfactant protein C gene (SFTPC) mutation-associated lung disease: high-resolution computed tomography (HRCT) findings and its relation to histological analysis. Pediatr Pulmonol 2010; 45: 1021-1029. 
Thouvenin G, Abou Taam R, Flamein F, et al. Characteristics of disorders associated with genetic mutations of surfactant protein C. Arch Dis Child 2010; 95: 449-454.

9 Turcu S, Ashton E, Jenkins L, et al. Genetic testing in children with surfactant dysfunction. Arch Dis Child 2013; 98: 490-495.

10 Avital A, Hevroni A, Godfrey S, et al. Natural history of five children with surfactant protein C mutations and interstitial lung disease. Pediatr Pulmonol 2014; 49: 1097-1105.

11 Hepping N, Griese M, Lohse P, et al. Successful treatment of neonatal respiratory failure caused by a novel surfactant protein C p.Cys121Gly mutation with hydroxychloroquine. J Perinatol 2013; 33: $492-494$.

12 Brasch F, Griese M, Tredano M, et al. Interstitial lung disease in a baby with a de novo mutation in the SFTPC gene. Eur Respir J 2004; 24: 30-39.

13 van Hoorn J, Brouwers A, Griese M, et al. Successful weaning from mechanical ventilation in a patient with surfactant protein C deficiency presenting with severe neonatal respiratory distress. BMJ Case Rep $2014 ; 2014$.

14 Choi Y, Sims GE, Murphy S, et al. Predicting the functional effect of amino acid substitutions and indels. PloS One 2012; 7: e46688.

15 Kumar P, Henikoff S, Ng PC. Predicting the effects of coding non-synonymous variants on protein function using the SIFT algorithm. Nat Protoc 2009; 4: 1073-1081.

16 Adzhubei IA, Schmidt S, Peshkin L, et al. A method and server for predicting damaging missense mutations. Nat Methods 2010; 7: 248-249.

17 Tafel O, Latzin P, Paul K, et al. Surfactant proteins SP-B and SP-C and their precursors in bronchoalveolar lavages from children with acute and chronic inflammatory airway disease. BMC Pulm Med 2008; 8: 6.

18 Griese M, Schumacher S, Tredano M, et al. Expression profiles of hydrophobic surfactant proteins in children with diffuse chronic lung disease. Respir Res 2005; 6: 80.

19 Hansell DM, Bankier AA, MacMahon H, et al. Fleischner Society: glossary of terms for thoracic imaging. Radiology 2008; 246: 697-722.

20 Jankowich MD, Rounds SI. Combined pulmonary fibrosis and emphysema syndrome: a review. Chest 2012; 141: $222-231$.

21 van Moorsel CH, van Oosterhout MF, Barlo NP, et al. Surfactant protein C mutations are the basis of a significant portion of adult familial pulmonary fibrosis in a Dutch cohort. Am J Respir Crit Care Med 2010; 182 : 1419-1425.

22 Cottin V, Reix P, Khouatra C, et al. Combined pulmonary fibrosis and emphysema syndrome associated with familial SFTPC mutation. Thorax 2011; 66: 918-919.

23 Hartl D, Griese M. Interstitial lung disease in children - genetic background and associated phenotypes. Respir Res 2005; 6: 32 .

24 Amin RS, Wert SE, Baughman RP, et al. Surfactant protein deficiency in familial interstitial lung disease. $J$ Pediatr 2001; 139: 85-92.

25 Lawson WE, Grant SW, Ambrosini V, et al. Genetic mutations in surfactant protein C are a rare cause of sporadic cases of IPF. Thorax 2004; 59: 977-980.

26 Shakir M, Lake M, Hillary $\mathrm{H}$, et al. Rare damaging variants in the surfactant Protein-C And ABCA3 genes in adult patients with idiopathic pulmonary fibrosis. D37 systems biology and molecular profiling in pulmonary health and disease. Am J Respir Crit Care Med 2011; 183: A6003.

27 McBee AD, Wegner DJ, Carlson CS, et al. Recombination as a mechanism for sporadic mutation in the surfactant protein-C gene. Pediatr Pulmonol 2008; 43: 443-450.

28 Baekvad-Hansen M, Nordestgaard BG, Tybjaerg-Hansen A, et al. Two novel mutations in surfactant protein-C, lung function and obstructive lung disease. Respir Med 2010; 104: 418-425.

29 Li J, Ikegami M, Na CL, et al. N-terminally extended surfactant protein (SP) C isolated from SP-B-deficient children has reduced surface activity and inhibited lipopolysaccharide binding. Biochemistry 2004; 43: 3891-3898.

30 Flamein F, Riffault L, Muselet-Charlier C, et al. Molecular and cellular characteristics of ABCA3 mutations associated with diffuse parenchymal lung diseases in children. Hum Mol Genet 2012; 21: 765-775. 